\title{
A Case With Type I Gaucher Primarily Involved Pelvis
}

\author{
Banu Dilek ${ }^{\mathrm{a}, \mathrm{b}}$, Fatma Aydınª, Ilknur Sevin Buluttekin Daga , Ibrahim Batmaz \\ Kemal Nas ${ }^{\mathrm{a}}$, Remzi Cevik ${ }^{\mathrm{a}}$
}

\begin{abstract}
Type 1 Gaucher disease is the most common lysosomal storage disorder which also affects the musculoskeletal system with various organ manifestations. Here, we aimed to present a case diagnosed Type 1 Gaucher disease which mainly involved pelvis.
\end{abstract}

Keywords: Type 1 gaucher disease; Sacroilitis; Vertebral compression fracture

\section{Introduction}

Gaucher disease is an autosomal recessive disorder and characterized by a deficiency of the enzyme $\beta$ - glucoserebrosidase. This is caused by progressive glucoserebroside collection within phagocyte cells of reticuloendothelial system. Especially liver, spleen, kidney, lung and bone marrow are affected [1]. Three major type of disease are identified. The adult form (Type 1) is the most common and non- neuronopathic form and charactirized by anemia, trombosytopenia, hepatosplenomegaly, bone pain and pathologic fractures. Type 2 is acute neuronopatic form and affects infants. There are early onset nervous system problems and early death in this form. Juvenile form (Type 3) is subacute neuronopathic form and identified later onset nervous system problems $[2$,

Manuscript accepted for publication December 30, 2011

${ }^{a}$ Department of Physical and Rehabilitation Medicine, Dicle University Hospital, Diyarbakır, Turkey

${ }^{\mathrm{b}}$ Corresponding author: Banu Dilek. Email: banu.dilek@deu.edu.tr

doi:10.4021/jem68e
3]. Gaucher disease is diagnosed with byopsi of involved organs or bone marrow [3]. Different findings in the musculoskeletal system may occur and differential diagnosis can be difficult in adults. Here, we aimed to present a case diagnosed Type 1 Gaucher disease which mainly involved pelvis.

\section{Case Report}

A 32-year-old male patient was admitted with complaints of right hip pain and restriction. Seven years ago, he had followed with the pancytopenia due to use of analgesics in the other center and had diagnosed as a myelonecrosis in bone marrow biopsy. His hip pain had started after this period and increased at last 4 months. The query of systemic, rheumatic and family history was unremarkable. In Physical examination, Fabere, Mennel, Thomas and sacroiliac compression tests were positive on the right. There was no tenderness in the regions of enthesitis. Low back movements were normal and extention was minimally painful. Neurological examination was natural. Chest expansion and modified Schober were measured $6 \mathrm{~cm}$. Laboratory tests in acute-phase reactants, blood count, biochemical tests, and hepatitis panel

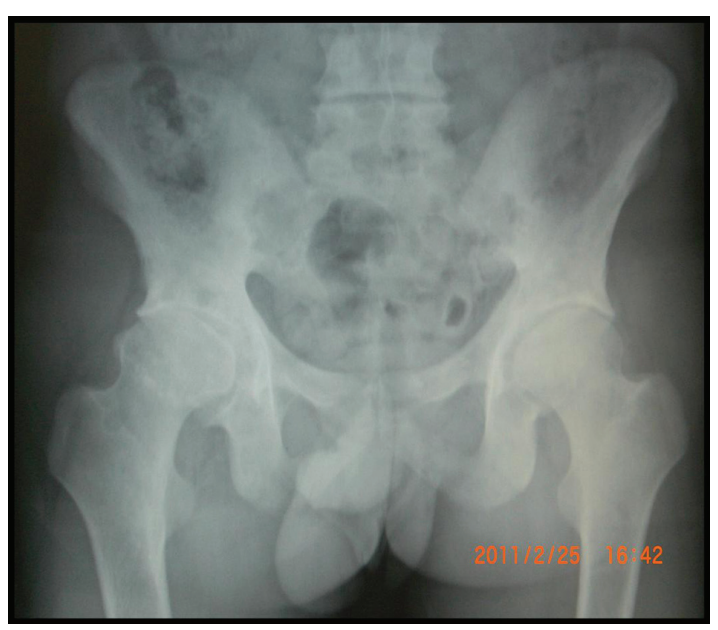

Figure 1. Right hip sclerosis, bilateral grade 3 sacroilitis in Pelvic X-ray. 


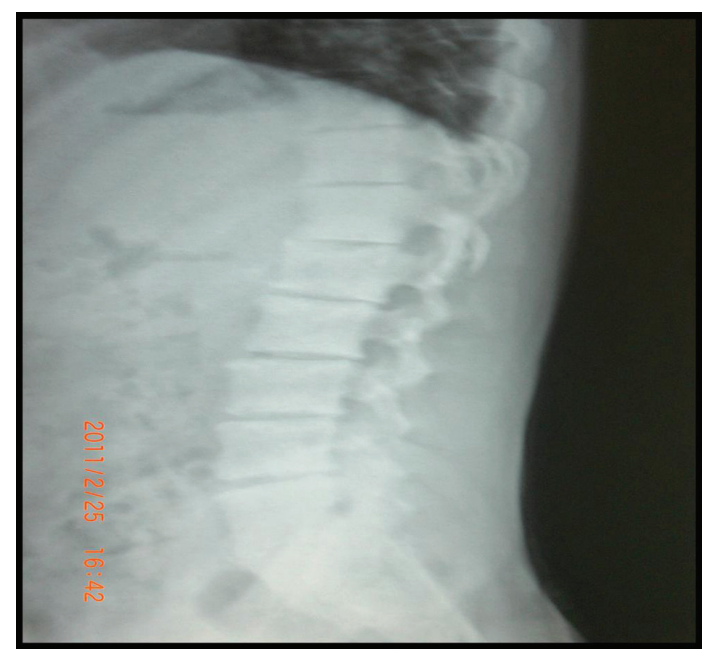

Figure 2. L1 compression fracture in lumbar spine X-ray.

were normal. Right hip sclerosis, bilateral grade 3 sacroiliitis were detected in Pelvic X-ray and the L1 compression fracture was detected in lumbar spine X-ray (Fig.1, 2).

Peripheral smear, tumor markers, tuberculin skin test, Brucella and salmonella tests and bone mineral density were normal. Splenomegaly was found in abdominal ultrasonography. Widespread sclerosis of bone structures and generally irregular enhancement bilaterally in sacroiliac joints and right hip after gadolinium injection in MRI. Also it was found common degeneration in all intervertebral spaces and compression fracture at L1 vertebrae (Fig. 3, 4, 5).

Clinical and radiologically; metabolic diseases, widespread abscesses and malignancy were not differentiated. Diastase resistant PAS (+) and CD68 (kp1)-positive cellular infiltration with Gaucher cells were detected in bone marrow biopsy.

Exercises of range of motion, stretching and isometric

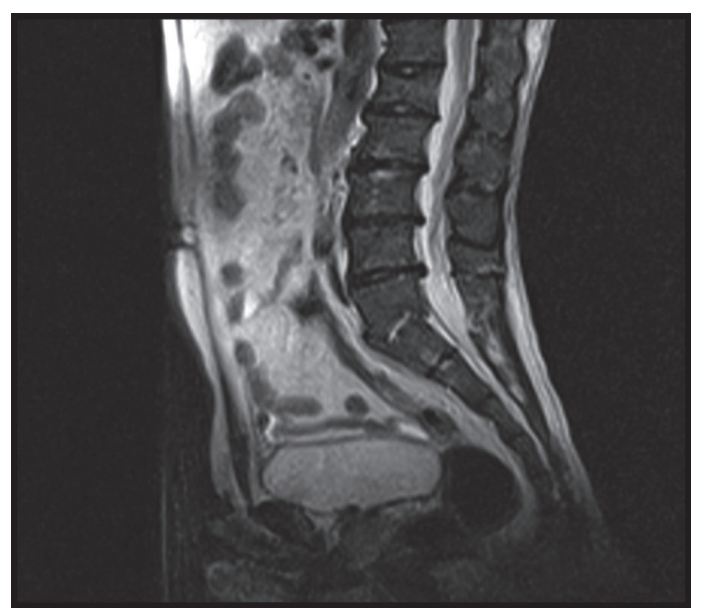

Figure 3. Lumber MRI: L1 compression fracture and dejenerations in all intervertebral.

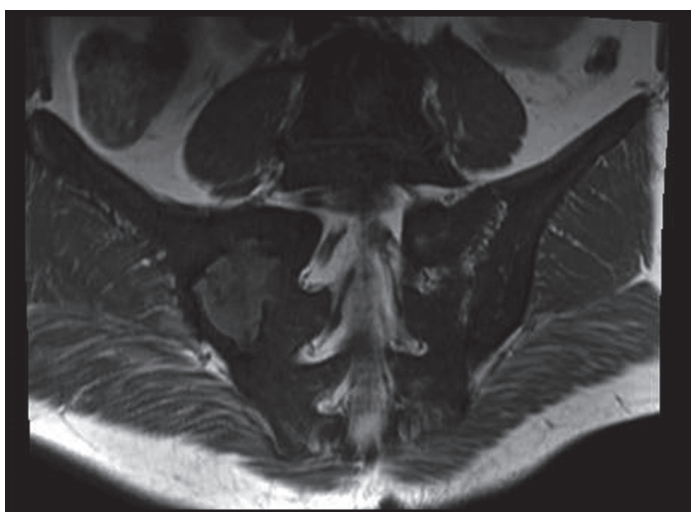

Figure 4. Sacroiliac MRI: Widespread sclerosis of bone structures and generally irregular enhancement bilaterally in sacroiliac joints.

with the application of TENS, and medically asemetazin 90 $\mathrm{mg}$ /day dose were started. The patient who had reduced pain was referred to hematology department for enzyme replacement therapy.

\section{Discussion}

Type 1 Gaucher disease is the most common lysosomal storage disorder. Incidence of this type is 1/40000-60000. The central nervous system is not affected in this form while the other organ systems are in different proportions [4]. Clinic signs of type 1 Gaucher disease may vary from patient to patient. Many mutataion in glucoserebrosidase enzym have described and the severity of disease can be exhibit differences [5]. Pancytopenia, elevated sedimentation and findings of spleen or bone marrow biopsy were used for diagnosis. Lately, diagnosis has become easier with measurement of enzym level and mutation detection. Because of a rarity of the disease diagnosis may be delayed. The main findings depend on the infiltration of the reticuloendothelial system.

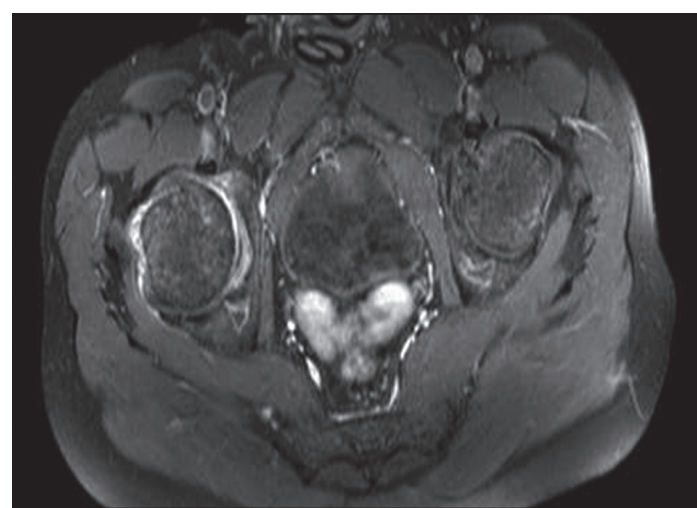

Figure 5. Pelvic MRI: right hip irregular enhancement after gadolinium injection in MRI. 
Disease commonly presents hepatosplenomegali, pansitopeni, osteopeni, osteonekroz and osteoskleroz with bone pain and fractures. It may also rarely involve cardiopulmonary and renal systems [6]. Hematologic findings include anemia, trombocytopenia, leukopenia, hypersplenisim and hepatomegaly. Hypersplenism sometimes reguire splenectomy. Hepatic fibrosis can rarely lead to liver failure and portal hypertension. Hepatic enzyms can be elevated [7]. Splenomegaly was detected by abdominal ultrasonography in patient. Laboratory tests were normal but in the patient's history severe pancytopenia and elevated sedimentation (100 $\mathrm{mm} / \mathrm{h}$ ) were detected.

Musculosceletal manifestations of Gaucher disease are variable. Erlenmeyer deformity is characterized by expansion in distal femur and proximal tibia metaphysis can be shown with X-Ray [8]. Bone infarcts can cause painful bone crisis and cause local swelling, high temperature and erythema. This condition may be confused with osteomyelitis. Acute crisis are seen in $10-32 \%$ of patients $[8,9]$. Affected chronic vascular circulation may lead to osteonecrosis. Therefore pathologic fractures can be seen in vertebrae, femur and humerus also may lead to femoral avasculer necrosis. Male gender, high platelet counts and osteonecrosis in another location are risk factors for progressive disease [10]. Sakroiliac sclerosis may occur because of osteosclerosis [6, 10]. We detected lumber compression fracture, hip sclerosis, bilateral grade 3 sacroiliitis in X-ray of our patient. We investigated seronegative spondyloarthritis (ankylosing spondylitis, psoriatic arthritis, Reiter's syndrome, Behçet's disease and inflammatory bowel disease), brucella, salmonella and other pyogenic enfections, methabolic diseases, malignancy and tuberculous for differential diagnosis of sacroileitis. The incidence of Gaucher disease increases with polyclonal gammopathy, multiple myeloma, lymphoma, bronchogenic carcinoma and amiloidosis because of immune deficiency [11].

Clinical features and bone marrow or affected organ biopsy are used for diagnosis. Metabolic disease, malignancy and infection could not be distinguished by MRI in patient. There is no specific diagnostic finding in MRI for this disease. However, T1 weighted MRI is useful for evaluating and following skeletal involvement after treatment. T2 weighted MRI is recommended for evaluating acute bone infarcts and osteomyelitis [12].

Medical treatment of Gaucher disease is enzyme replacement therapy. On the other hand, opioid therapy is used in acute painful crisis, bisphosphonates and calsium- D vitamins are used for osteoporosis [13]. Physical therapy modalities and exercises can reduce pain and restriction of joint. Musculoskeletal manifestations sometimes need ortopeadic surgery [14]. Hip and knee arthroplasties can be performed because of severe pain and loss of function. Our patient had restriction of hip joint but had not kyphotic posture. His pain was decreased by physical therapy and exercise program.

Gaucher disease causes disabilty and poor quality of life in patients of all ages. This disease should be considered in the differential diagnosis of diseases presenting with various musculoskeletal involvement and causing chronic pain and limitations.

\section{Conflict of Intrest}

None.

\section{References}

1. Lutsky KF, Tejwani NC. Orthopaedic manifestations of Gaucher disease. Bull NYU Hosp Jt Dis. 2007;65(1):3742.

2. Mankin HJ, Rosenthal DI, Xavier R. Gaucher disease. New approaches to an ancient disease. J Bone Joint Surg Am. 2001;83-A(5):748-762.

3. Chen M, Wang J. Gaucher disease: review of the literature. Arch Pathol Lab Med. 2008;132(5):851-853.

4. Wegner D, Hug G, Rezvani I. Disorders of mucopolysaccharide metabolism. In: Berhman RE, Vaughan VC (eds). Nelson Textbooks of Pediatrics. Philedelphia: WB-Saunders, 1992: 333-334.

5. Cox TM. Gaucher disease: understanding the molecular pathogenesis of sphingolipidoses. J Inherit Metab Dis. 2001;24 Suppl 2:106-121; discussion 187-108.

6. Karatepe AG, Günaydın R, Kaya T, Şen N, Özbek G, Esen ÖS. Skeletal manifestations in Gaucher Disease: A case report. Osteoporoz Dünyasından. 2005;11:127131.

7. Zimran A, Kay A, Gelbart T, Garver P, Thurston D, Saven A, Beutler E. Gaucher disease. Clinical, laboratory, radiologic, and genetic features of 53 patients. Medicine (Baltimore). 1992;71(6):337-353.

8. Charrow J, Andersson HC, Kaplan P, Kolodny EH, Mistry P, Pastores G, Rosenbloom BE, et al. The Gaucher registry: demographics and disease characteristics of 1698 patients with Gaucher disease. Arch Intern Med. 2000;160(18):2835-2843.

9. Sziklas JJ, Negrin JA, Rosshirt W, Rosenberg RJ, Spencer RP. Diagnosing osteomyelitis in Gaucher's disease. Observations on two cases. Clin Nucl Med. 1991;16(7):487-489.

10. Deegan PB, Pavlova E, Tindall J, Stein PE, Bearcroft P, Mehta A, Hughes D, et al. Osseous manifestations of adult Gaucher disease in the era of enzyme replacement therapy. Medicine (Baltimore). 2011;90(1):52-60.

11. Gery I, Zigler JS, Jr., Brady RO, Barranger JA. Selective effects of glucocerebroside (Gaucher's storage material) on macrophage cultures. J Clin Invest. 1981;68(5):11821189.

12. Maas M, Poll LW, Terk MR. Imaging and quantifying 
skeletal involvement in Gaucher disease. Br J Radiol. 2002;75 Suppl 1:A13-24.

13. Pastores GM, Patel MJ, Firooznia H. Bone and joint complications related to Gaucher disease. Curr Rheu- matol Rep. 2000;2(2):175-180.

14. Kocher MS, Hall JE. Surgical management of spinal involvement in children and adolescents with Gaucher's disease. J Pediatr Orthop. 2000;20(3):383-388. 